Canadian

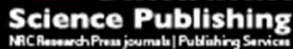

Canadian Geotechnical Journal Revue canadienne de géotechnique

\title{
Study on the efficiency of destress blasting in deep mine drift development
}

\begin{tabular}{|r|l|}
\hline Journal: & Canadian Geotechnical Journal \\
\hline Manuscript ID & cgj-2016-0260.R1 \\
\hline Manuscript Type: & Article \\
\hline Date Submitted by the Author: & 06-Sep-2016 \\
\hline Complete List of Authors: & $\begin{array}{l}\text { Sainoki, Atsushi; McGill University, Mining \& Materials Engineering } \\
\text { Emad, Muhammad Zaka; UET Lahore, Mining Engineering } \\
\text { Mitri, Hani; McGill University, }\end{array}$ \\
\hline Keyword: & numerical modelling, Flac3D, rock burst, underground mining \\
\hline
\end{tabular}

\section{SCHOLARONE ${ }^{\text {m }}$ \\ Manuscripts}


Study on the efficiency of destress blasting in deep mine drift development Atsushi Sainoki ${ }^{1}$, Muhammad Zaka Emad ${ }^{* 2}$, and Hani S. Mitri ${ }^{1}$

${ }^{1}$ Department of Mining and Materials Engineering, McGill University, Canada

${ }^{2}$ Department of Mining Engineering, UET Lahore, Pakistan

\begin{abstract}
Canadian hard rock mines continue to reach deeper deposits, which poses greater challenges to mine safety including rock burst control. Destress blasting techniques have been successfully employed in such underground mines with the aim of preconditioning highly stressed rock mass to mitigate the risk for rock burst occurrence in deep mines. In the present study, the efficiency of destress blasting is examined through a comparison between traditional and alternative numerical modelling approaches. The traditional modelling approach assumes a uniformly distributed blast-induced damage zone extending over the entire drift face, whilst the alternative modelling approach, presented herein, simulates the damage zone for each individual blast hole. In the first part of this paper, a 3-D numerical model of a single blast hole is constructed, whereby the extent of blast-induced damage zone is delineated. The latter part of this paper uses the single-hole model results to examine the efficiency of destress blasting as practiced in drift development in deep mines. It is demonstrated through comparison of FLAC3D numerical simulation results that the traditional modelling approach may lead to an overly optimistic indication of destress blasting efficiency when compared with the alternative modelling approach, in which a more precise simulation of the damage zones is applied.
\end{abstract}

Keywords: numerical modelling; FLAC3D; rock burst; underground mining.

Corresponding author: Muhammad Zaka Emad

Email: zaka@uet.edu.pk 


\section{$1 \quad$ Introduction}

2 When tunnels are excavated through competent rock mass under high stress conditions, rock

3 bursts, especially strain bursts, can be a serious issue that poses a high risk to underground 4 workers (Abdellah et al. 2013; Mazaira and Konicek 2015; Qiu et al. 2014; Zhang et al. 2014). In

5 order to reduce the risk, the destress blasting technique has been widely applied in underground

6 mines all over the world (Andrieux et al. 2003; Konicek et al. 2013; Mitri and Saharan 2005;

$7 \quad$ Saharan and Mitri 2011; Tang and Mitri 2001; Zhu et al. 2013). It was first developed in the

8 Witwatersrand gold mines in South Africa (Roux et al. 1957). Stress field in the rock mass ahead

9 of the mining face is reduced by practicing destress blasting which reduces the risk of rock bursts

10 while drilling and loading explosives. The aim of destress blasting is to reduce high stress in the

11 rock mass immediately ahead of the mining face. Stress accumulation in rock mass may ascend

12 due to greater depths, mining activities and geologically stiff material.

13 Destress blasting is practiced by drilling and blasting a specific pattern in highly stressed rock

14 mass with relatively smaller explosive charge, prior to the development or production mining

15 cycle. Depending on the application, borehole length, charge length, number and pattern may

16 vary for better results. In situations like face advancement (mine development drifts, crosscuts

17 and tunnels), the length of destress blasting hole is greater than the usual production blasting hole.

18 Thus destress blasting is conducted behind the working face. Destress blasting is followed by the

19 main development blast which exposes the destressed zones. The procedure is repeated and the

20 rock stress is relieved for greater safety at the working face. The pattern of destress blasting varies

21 with the application. It is always performed in the high stress and high energy zones in mines.

22 When the destress blasting is integrated with the mining cycle, the repeated destressing blasting

23 practice ensures that the immediate rock face is stress-relieved.

24 Destress blastholes are charged at the bottom of the blasthole and the charge length is kept small 25 compared to the entire length of the borehole. Also, destress blasting holes are longer than the 26 regular production holes and destress blasting holes are fired prior to the main blasting round.

27 Destress blastholes are fired under confined environment with no free face and thus they are 28 different from the main development blasting holes. The stress profile behind the mine drift face 29 is shown in Fig. 1. It can be seen that the stresses decrease, away from the mining face with a 30 minimum value equal to pre-mining stresses. Also the stresses are reduced after implementation 31 of destress blasting at the drift face.

33 Figure 1. Stress profile ahead of a destressed drift face, modified after Tang (2000).

34 Although the effectiveness of destress blasting can be investigated and verified through in-situ 
observations such as stress measurements and microseismic activity monitoring before and after the implementation of destress blasting (Andrieux et al. 2003; Konicek et al. 2013), it is conceivable that tremendous efforts are occasionally required to obtain an ideal blasting design, such as a hole diameter and an explosive charge length, to maximize the efficiency of destress blasting and minimizes damage to the surrounding openings. Thus, it is suggested that numerical modelling techniques can be employed in conjunction with the field measurements. In fact, extensive studies have been undertaken with a variety of numerical simulation techniques to investigate the effect of destress blasting (Blake 1972; Bolstad 1990; Saharan and Mitri 2009; Tang and Mitri 2001; Zhu et al. 2013). Blake (1972) proposes a parameter, $\alpha$, which represents a reduction in the modulus of elasticity of rock mass preconditioned by destress blasting. Tang and Mitri (2001) further propose a stress dissipation factor, $\beta$, which represents instantaneous stress release in the preconditioned rock mass. These parameters are applied to a numerical model, whereby stress re-distribution induced by destress blasting is simulated in the model, giving a clue to the efficiency of destress blasting.

Taking in view the increasing demand for mineral resources, it is envisioned that mining activities will become more intensive at significantly great depths in the near future. Hence, the importance of techniques that can mitigate risks for rock bursts is expected to increase furthermore. Guidelines to perform destress blasting effectively in a proper manner need to be established. This paper puts on emphasis on clarifying a study problem with respect to the effectiveness of destress blasting from the previous study. In order to address the issue, the extent of damage zones induced by destress blasting is examined, using a numerical model with a single blast hole in dynamic conditions. In particular, the present study focuses on destress blasting performed in granite and norite. This is because i) granite has been studied for a long time with laboratory experiments and numerical analyses as the causative rock for strain bursts (Hongjian et al. 2015; Wang and Park 2001; Zhao and Cai 2014) and ii) rock bursts have been reported also in the rock mass composed of norite with high stiffness in a deep hard rock mine in Canada (Malek et al. 2009; Snelling et al. 2013). Subsequently, destress blasting practice used by industry is examined with a numerical model encompassing a single drift whilst taking into account the estimated extent of damage zone.

\section{Study problem and objective}

Tang and Mitri (2001) simulate stress re-distribution induced by destress blasting for examining its effect on in-situ stress state around a drift face excavated in hard rock under high stress conditions. Their paper employs the parameters $\alpha$ and $\beta$, defined above to simulate the Geomechanical effects of destress blasting. These are applied to a numerical model encompassing a drift. The study clearly shows that the stress concentrations taking place ahead of the drift face 
are alleviated with destress blasting, thereby decreasing the potential for rock bursts. The methodology adopted by Tang and Mitri (2001) is simple, in that there is no need to model the actual blastholes in the numerical model to obtain the effect destress blasting. The parameters to simulate preconditioned rock mass are applied to specific zones (drift face) in the numerical model, where the rock mass is presumed to be fractured and destressed by the blasting.

However, the methodology adopted by Tang and Mitri (2001) is valid only when the extent of damage zones (destressed zones) to which the parameters are applied is estimated accurately. As shown in Fig. 2, better understanding of destressed zones around blastholes is critical in obtaining a suitable simulation of preconditioning highly stressed rock mass. The present study aims at estimating the extent of damage zones induced by destress blasting more accurately using a single-hole, 3D model. The results obtained from the single-hole model are then used in a larger scale 3D model of a mine drift for the simulation of destressed zones in a drift face subjected to destress blasting.

Figure 2. Schematic diagram showing damage zones induced by destress blasting.

\section{Methodology}

The present study constructs a 3-D numerical model with a single blast hole, using FLAC3D (Itasca 2009), a three-dimensional explicit finite-difference program. Static analysis is first performed so as to simulate the in-situ stress state at a deep underground mine. Subsequently, destress blasting is simulated in the model under dynamic conditions while applying time-varying radial pressure to the surface of the blasthole. In order to realize the proper simulation and evaluation of damage zones induced by the destress blasting, a constitutive model that allows for the strain-rate dependency of the uniaxial compressive strength (UCS) and tensile strength of rock is newly implemented into FLAC3D codes with $\mathrm{C}++$ programming language. Detailed descriptions on the aforementioned model and analysis procedure are given in the following sections.

\section{Numerical model}

Fig. 3 shows the numerical model constructed with FLAC3D codes. As can be seen in the figure, the diameter and length of the blasthole are $0.1 \mathrm{~m}$ and $6 \mathrm{~m}$, respectively. According to Mitri (2001), the diameter of a blast hole for destress blasting ranges from $38 \mathrm{~mm}$ to $140 \mathrm{~mm}$. In the range, a diameter of $100 \mathrm{~mm}$ was adopted in the present study as a representative dimension for destress blasting. Peak borehole pressure is strongly dependent on the blast hole diameters (Saharan and Mitri 2009). Hence, although the present study models the blasthole with a diameter of $100 \mathrm{~mm}$, it is suggested as future work to simulate destress blasting with different blast hole 
105

106

107

108

109

110

111

112

113

114

115

116

117

118

119

120

121

122

123

124

125

126

127

128

129

130

131

132

133

134

135

136

137

138

139

diameters and to investigate its influence on the extent of blast-induced damage zones.

In general, face destress blasting is performed to reduce stress concentrations and to generate fractured zones ahead of a drift face. Thus, the length of blast holes for destress blasting is designed to be longer than that of blast holes for drift developments; and a blasted area is limited to several feet from its toe, which is site-specific depending on rock mass characteristics, geological conditions and drift advance rate. The present study employs two explosive charge lengths, $0.6 \mathrm{~m}$ and $0.9 \mathrm{~m}$. The charge lengths are determined based on practices in a deep hard rock mine located in Sudbury, Canada. Fig. 3 shows a model with 0.9 m charge length (3 feet), which is used to investigate general characteristics of the extent of blast-induced damage zones.

In order to replicate the extent of damage zones due to destress blasting as accurately as possible, extremely fine meshes are generated in the radial direction around the blast hole. The length of the densely discretized meshes is approximately $1 \mathrm{~cm}$ in the vicinity of the blasthole; and it increases towards the model outer boundaries. The total numbers of zones and grid points in the model are 576000 and 590431, respectively. Computation time to perform the static and dynamic analyses is approximately 30 hours when a personal computer with $4.0 \mathrm{GHz}$ CPU and 32 GB RAM is used. Considering the balance between the computation time and the accuracy of results, the aforementioned numerical model is constructed.

Figure 3. Numerical model: (a) sectional view; (b) longitudinal sectional view.

\section{Blast pressure profile}

To date, a number of formulae have been developed and used to replicate time-varying blast pressure due to detonation and gas expansion (Cho et al. 2003a; Lima et al. 2002; Liu and Katsabanis 1997) as reviewed by Saharan and Mitri (2009). Among them, the Jones-Wilkens-Lee (JWL) equation of state is widely used because of its simplicity (Itoh et al. 2002; Wang et al. 2007; Wei and Zhao 2008). For instance, Wang et al. (2007) simulate a crater induced by a blast in brittle rock while applying blast pressure obtained from JWL equation of state. In other studies, decay functions are employed to simulate time-decaying blast pressure (Emad et al. 2014; Gool 2007; Jiang et al. 1995; Sainoki and Mitri 2014; Zhu et al. 2013). Saharan and Mitri (2009) point out that parameters used in these equations are difficult to obtain for the non-ideal detonation of ANFO type explosives that are often used for destress blasting in underground mines. Furthermore, the authors indicate that the physical significance of parameters used in the decay functions is unknown. Thus, the present study adopts an optimized blast pressure profile proposed by Saharan and Mitri (2009). As the optimized blast pressure is proposed for 2-D analysis, the propagation of detonation along the blasthole is newly taken into consideration in this study. A 
140 similar optimized blast pressure function is found in other studies, e.g., Sharafisafa and Mortazavi 141 (2011) examine the effect of stress waves induced by a blast on a fault, using an optimized, simple 142 blast pressure profile.

143 Fig. 4 depicts the load amplitude of the optimized blast pressure profile, by which peak borehole 144 pressure is multiplied before being applied to the blast hole surface. The load amplitude takes the 145 maximum value $100 \mu$ s after the onset of a blast. Afterwards, it drastically decreases as shown in 146 the figure. Although the optimized profile is proposed for a $38 \mathrm{~mm}$ diameter borehole, the same 147 profile is used in the present study. As a dominant factor that determines the rise time of explosion 148 pressure is a type of explosives (Saharan and Mitri 2009), the proposed pressure profile is 149 assumed to be applicable to the current model.

150 As mentioned earlier, it is necessary to consider the propagation of detonation along the blast hole 151 for 3-D analysis. The time at which radial pressure starts to rise at a given point, "A", in Fig. 4 is 152 calculated by dividing the distance between the point and the toe of the blasthole by detonation 153 velocity. In this study, ANFO is presumed to be the explosive for destress blasting. According to 154 Adams et al. (1993), velocity of detonation is $4700 \mathrm{~m} / \mathrm{s}$ when ANFO explosive is blasted in 76 155 and $86 \mathrm{~mm}$ diameter boreholes. In this study, the same value is used. Saharan and Mitri (2009) 156 estimate the peak borehole pressure of ANFO explosive at 2.5 GPa when the diameter of a 157 borehole is 76 and $89 \mathrm{~mm}$. The value is adopted; and it is multiplied by the load amplitude shown 158 in Fig. 4 during the dynamic analysis. In this way, time-varying blast pressure applied to the 159 surface of the blasthole is computed.

Figure 4. Optimized pressure profile for ANFO type explosive for a $38 \mathrm{~mm}$ diameter borehole and 163 schematic diagram showing propagation of detonation.

\section{Material properties}

As discussed, the present study investigates destress blasting performed in the rock mass composed of granite and norite. Table 1 lists the mechanical properties for both the rock types. In the table, modulus of elasticity, $E$, uniaxial compressive strength, $\sigma_{\mathrm{c}}$, Poisson's ratio, $v$, and unit weight of rock mass, $\gamma$, are the mechanical properties of granite and norite derived from the case study conducted by Malek et al. (2009). The friction angle, $\phi$, of granite is based on the triaxial tests of granite performed by Yun (2008), while the friction angle of norite is estimated from the friction angle and uniaxial compressive strength of African norite reported by Vanichkobchinda et al. (2007). The tensile strength, $\sigma_{\mathrm{T}}$, is estimated from the UCS, using the equation developed by Altindag and Guney (2010). The dilation angle $\psi$ is set to $8.75^{\circ}$ for both the rock types in this study. Importantly, during the dynamic analysis, the rock strength increases with strain rate as 
175

176

177

178

179

180

181

182

183

184

185

186

187

188

189

190

191

192

193

194

195

196

197

198

199

200

201

202

203

204

205

206

207

208

209

strain rate dependency is taken into consideration.

Table 1. Rock mass mechanical properties.

\section{Constitutive model to simulate strain rate dependency on compressive and tensile strength}

It is well-known that the compressive and tensile strengths of rock have strain rate dependency. As a significantly high strain rate is expected to be induced by the dynamic blast loads, it is imperative to allow for the strain rate dependency of rock strength. To date, extensive studies have been undertaken to examine the characteristics of rock strength under high strain rates (Cho et al. 2003c; Hao and Hao 2013; Kubota et al. 2008; Lajtai et al. 1991; Li et al. 2013; Wu et al. 2012; Xia 2013; Zhao et al. 2014). As can be seen in the studies, the strain rate dependency varies depending on rock types. More importantly, as pointed out by Hao and Hao (2013), the dynamic increase factor (DIF) obtained from experiments is susceptible to a number of factors, such as lateral inertia confinement, friction confinement between the specimen and impact materials, and the size and geometries of the specimen. Hao and Hao (2013) collect DIFs from previous studies and propose an empirical relation between DIF and strain rate for the compressive strength of granite after eliminating the effect of lateral inertia confinement. The proposed relation is employed in this study. In addition, the authors derive the best-fitted curve that represents DIF for the tensile strength of rock. Although the fitted curve is computed without considering rock types, it is adopted in this study due to lack of information. These relations are expressed as follows:

$$
C D I F=0.018668(\log \dot{\varepsilon})+1.291887 \text { for } 1 s^{-1} \leq \dot{\varepsilon} \leq 220 s^{-1}
$$

$C D I F=1.8547(\log \dot{\varepsilon})^{2}-7.9014(\log \dot{\varepsilon})+9.6674 \quad$ for $220 s^{-1} \leq \dot{\varepsilon} \leq 1000 s^{-1}$

$$
T D I F=0.059805(\log \dot{\varepsilon})+1.35883 \text { for } 10^{-6} s^{-1} \leq \dot{\varepsilon} \leq 0.1 s^{-1}
$$

$T D I F=0.560483(\log \dot{\varepsilon})^{2}+1.387057(\log \dot{\varepsilon})+2.125599$ for $0.1 s^{-1} \leq \dot{\varepsilon} \leq 50 s^{-1}$

where CDIF and TDIF are DIFs for compressive strength and tensile strength, respectively; $\dot{\varepsilon}$ is strain rate. It is found from Equation (1) that CDIF cannot be calculated when strain rate is less than $1 \mathrm{~s}^{-1}$. However, strain rate dependency still exists when strain rate is below the level. Hence, in the dynamic analysis, Equation (1) is applied when $10^{-6} \mathrm{~s}^{-1} \leq \dot{\varepsilon} \leq 220 \mathrm{~s}^{-1}$, otherwise a great gap occurs at the moment that strain rate falls below $1 \mathrm{~s}^{-1}$. Both CDIF and TDIF are set to 1.0 when strain rate falls below $10^{-6} \mathrm{~s}^{-1}$. When strain rate exceeds the maximum value in the range $\left(1000 \mathrm{~s}^{-1}\right.$ for CDIF and $50 \mathrm{~s}^{-1}$ for TDIF), CDIF and TDIF calculated by substituting the maximum value into Equation (1) and (4) are used in order to avoid overestimating the dynamic strength.

It appears that there is no substantial information available to investigate the strain rate dependency on the internal friction angle and cohesive strength of rock. Thus, the present study assumes that the internal friction angle of granite is not affected by strain rate. During the dynamic 
210 analysis, the UCS in Table 1 is multiplied by the computed CDIF, which results in an increase in

211 cohesive strength. Regarding the tensile strength, it is simply multiplied by the TDIF.

212 The Mohr-Coulomb model implemented into FLAC3D model is accordingly modified with C++

213 programming language so that the change in the cohesive and tensile strengths is taken into

214 consideration during the dynamic analysis. When the failure criterion is satisfied, either CDIF or

215 TDIF is set to 1.0, depending on the failure type, e.g., if shear failure takes place, CDIF is set to

216 1.0. After that, perfect elasto-plastic behaviour is simulated.

217 Granite and norite are known to exhibit brittle behaviour, especially under uniaxial 218 stress condition. However, as confining stress increases, the behaviour becomes more 219 ductile, known as brittle-ductile transition (Jaeger et al. 2007). For instance, quartzite is 220 known for its brittle behaviour, but it behaves in almost a perfect elasto-plastic manner 221 when confining stress reaches $50 \mathrm{MPa}$. Destress blasting is generally performed within 222 a massive rock mass subjected to high compressive stress. In this study, confining stress 223 (minimum principal stress) is about $44 \mathrm{MPa}$ at a depth of $1500 \mathrm{~m}$, under which the rock 224 mass is expected to behave in a more ductile manner. Therefore, the use of the perfect 225 elasto-plastic model would be acceptable and reasonable.

Initial stress state

227 As this study focuses on destress blasting performed in a deep underground mine, the in-situ 228 stress state simulated in the numerical model is derived from the case study of a deep hard rock 229 mine in Canada (O'Donnell 1992). Vertical and horizontal stresses at a given mining depth are 230 calculated with the following equations:

$231 \sigma_{1}=0.042 \times D+10.35$

$232 \sigma_{2}=0.033 \times D+8.69$

$\sigma_{3}=0.029 \times D$

234 where $\sigma_{1}, \sigma_{2}$, and $\sigma_{3}$ denote the maximum horizontal stress, the minimum horizontal stress, and

235 vertical stress, respectively; $D$ represents a depth from the surface. It is to be noted that the unit of 236 calculated stresses from those equations is "MPa". In this study, the stress state at a mining depth 237 of $2000 \mathrm{~m}$ is applied to the model as an initial stress state.

238

239

240

241

242

243

\section{Analysis procedure}

First, static analysis is carried out, in which the maximum and minimum horizontal stresses calculated from Equations (5) and (6) are applied to the lateral boundaries, and the vertical stress calculated from Equation (7) is applied to the upper boundary. The orientation of the maximum horizontal stress is perpendicular to the blast hole. The bottom boundary of the model is fixed in 
the z-direction. The static analysis is continued until the maximum unbalanced force in the model becomes negligible. Based on the stress state obtained from the static analysis, dynamic analysis is carried out while applying the time-varying blast pressure to the surface of the blasthole. The boundary conditions applied in the static analysis are changed to viscous when the dynamic analysis starts, in order to prevent stress waves generated by the blast pressure from reflecting on the model boundaries.

A timestep used in the dynamic analysis is automatically optimized on the basis of the volume of each zone of the model, P-wave velocity derived from the rock mass mechanical properties, and the face area of each zone (Itasca 2009). The actual time step used during the dynamic analysis is $1.421 \times 10^{-8} \mathrm{~s}$. The dynamic analysis is continued until $0.002 \mathrm{~s}$. Considering the detonation velocity and optimized pressure profile, the time is deemed sufficient to capture damage zones induced by the blast.

\section{Damage criteria}

Tang and Mitri (2001) evaluate the efficiency of destress blasting with numerical analysis, in which special parameters are applied to blast-induced fractured (damage) zones. It is to be noted that the damage zones are assumed without any verification. In order to make the evaluation more reliable, the extent of damage zones, to which the parameters are applied, has to be estimated in a more appropriate manner. To date, a number of damage criteria related to blast vibrations have been developed. Brinkmann (1987) proposes a chart describing the relation between peak particle velocity and blast-induced damage to rock mass. Saharan and Mitri (2009) introduce fracture length parameters to assess the extent of damage zones induced by blasts. Zhu et al. (2013) examine the degradation of the modulus of elasticity due to tensile and shear failures to investigate damage zones after destress blasting. In the present study, as rigorous relations between strain rate and the failure strength of rock in tension and shear are employed, damage zones are examined with the extent of yielding zones due to tensile and shear failures around the blasthole.

\section{Results and discussion}

\section{Extent of damage zones}

First, the extent of damage zones is examined, with cross sections A, B, and C illustrated in Fig. 3, in order to gain a better understanding of its general characteristics. The model used has a charge length of $0.9 \mathrm{~m}$ and the mechanical properties of granite. It can be seen from the figure that the cross sections are located $0.3 \mathrm{~m}, 0.6 \mathrm{~m}$, and $0.9 \mathrm{~m}$ away from the toe of the blast hole, respectively.

Fig. 5 shows the extent of damage zones on the cross sections. The characteristic noticed from Fig. 5 is that the damage (yielding) zones extend deeper to the surrounding rock in the x-direction than in the z-direction, and the characteristic appears more noticeable on the cross sections A and B. As 
can be seen in Fig. 5(a), the damage zone extends up to $0.55 \mathrm{~m}$ from the center of the blast hole in the $\mathrm{x}$-direction, while it extends only $0.3 \mathrm{~m}$ from the blast hole in the $\mathrm{z}$-direction. It is deduced that the difference in confining stress between the $\mathrm{x}$ - and z-direction contributes to the different extent of the damage zone. As the blast pressure is applied perpendicular to the wall of the blast hole, the confining stress (minimum principal stress) is $\sigma_{\mathrm{zz}}$ in the region where the stress waves resulting from the blast pressure propagate in the horizontal direction from the side wall, although, in the vicinity of the side wall, $\sigma_{\mathrm{yy}}$ is the minimum principal stress because of the stress re-distribution caused by the blast hole. On the other hand, in the region where the stress waves propagate in the vertical direction from the crown of the blasthole, either $\sigma_{\mathrm{yy}}$ or $\sigma_{\mathrm{xx}}$ acts as the confining stress, depending on the propagation of blast-induced stress waves. This is because when the first compression waves propagate in the vertical direction, the confining stress is $\sigma_{y y}$, whereas there is a possibility of $\sigma_{\mathrm{xx}}$ acting as the confining stress when tangential tensile stress occurs after the first compression waves pass over (Zhu et al. 2007). As indicated in section 3.4, the maximum and minimum horizontal stresses are greater than the vertical stress, $\sigma_{z z}$, suggesting that the occurrence of shear failure is controlled in the area where the horizontal stresses act as the confining stress. As shown in Fig. 5, the difference in the extent of damage zones between the xand z-direction in cross section $\mathrm{C}$ is not as clear as in cross section A. It is speculated that this is because the in-situ stress states are significantly disturbed due to the stress re-distribution associated with the elasto-plastic behaviour of the rock mass that occurred before the detonation reaches the location of cross section $\mathrm{C}$.

Figure 5. Extent of damage zones on cross sections, simulated with the model with $0.9 \mathrm{~m}$ charge length and the mechanical properties of granite: (a) damage zone on cross-section A shown in Fig. 3; (b) damage zone on cross-section B; (c) damage zone on cross-section B.

Another observation from the figure is the tensile failure which extends in the radial direction from the blast hole. Radial cracks extending from the blast hole are simulated and reported in previous studies (Banadaki and Mohanty 2012; Cho et al. 2003b; Zhu et al. 2013; Zhu et al. 2007). As discussed in previous studies, after radial compressive stress due to the applied blast pressure passes, tangential tensile stress takes place, inducing tensile cracks and fractures. As found in Fig. 5 , the damage zone due to shear failure is more pronounced than that due to tensile failure. Therefore, further discussion on the development of tensile failure is not conducted in the present study.

\section{Damage zones of granite and norite used for a 3D model encompassing a drift}

The following sections utilize $3 \mathrm{D}$ configurations of the damage zones, for granite and norite, 
315 induced by destress blasting with $0.6 \mathrm{~m}$ charge length at a mining depth of $2000 \mathrm{~m}$. The damage 316 zones for both types of rock are almost identical, although the extent of damage zones for norite is 317 slightly larger. The volume of damage zones for granite and norite is $0.77 \mathrm{~m}^{3}$ and $0.83 \mathrm{~m}^{3}$, 318 respectively. Those results are reasonable as the uniaxial compressive strength and tensile 319 strength of granite are smaller than those of norite as shown in Table 1. Using the 3D shapes, the 320 efficiency of destress blasting is examined with a 3D model encompassing a drift in the latter part 321 after simplifying the geometry of the damage zones. The simplification is indispensable as modelling exactly the same geometry of damage zones in the 3D model with a drift requires dense mesh discretization near the damage zones for each blasthole, thereby resulting in increase in computation time. Also, considering the application of the results to other case studies, approximating and simplifying the geometry of damage zones would be inevitable. In the present study, it is proposed to simplify the damage zones with an ellipsoid. As discussed in the previous section for Fig. 5, the shapes of the damage zones on the cross sections appear to be elliptical. Considering the fact, the simplification to an ellipsoid would be acceptable.

The developed simulation method in the present study makes it possible to estimate the extent of damage zones around the blast hole in a simple manner, considering time-varying blast pressure and strain rate dependency on the strength of rock. From a practical perspective, this method is useful and applicable to any cases. Whether or not the rock mass is appropriately destressed depends on many factors, such as stress states and rock mass properties, which could significantly vary even in the same mine. With this method, estimating damage zones around blast holes for destress blasting is straightforward. More importantly, the estimated extent of damage zones can be used with the method to evaluate the effectiveness of destress blasting employed by Tang and Mitri (2001), which is discussed in following sections.

A Canadian hard rock mine located in Sudbury, Ontario, is considered as the case study for this work. The mine is very deep and has been experiencing the problem of strain bursts for quite a while. High stress in tandem with stiff country rock and ore bodies makes the conditions adverse for mine safety and efficient extraction of ore. The mine practices destress blasting technique for tackling high stresses and thus reducing the potential for strain burst. The common destress blasting practice of the mine is to destress the high stress zone one round behind the drift face and then initiating the main blast for drift development. The destressed zones are exposed after the main blast. 
351 The typical destress blasting pattern employed by the case study mine consists of six blast holes as shown in Fig. 6. Two of the long blast holes for destress blasting are drilled parallel to the horizontal axis of the drift, at mid-height of the drift. The two side holes of destress blasting pattern are drilled horizontally at an angle of 45 degrees from the drift walls, at a height of $0.6 \mathrm{~m}$ from floor. The two corner holes of destress blast are drilled near the top corners of the drift at an angle of 45 degrees from the longer horizontal axis and 60 degrees from vertical axis of drift. The parameters for destress blasting are shown in Table 2.

Table 3 lists model input parameters related to geotechnical properties and destress blasting simulation, i.e., fracturing and stress re-distribution. Regarding the geotechnical data, the same properties as those used in the previous sections are adopted; it should be noted, however, that numerical analyses to simulate the destress blasting practice are performed under elastic conditions in accordance with the methodology proposed by Tang and Mitri (2001).

Table 2. Destress blast hole specification chart.

Table 3. Input parameters for numerical model.

\section{Numerical modelling of destress blasting}

The rock fragmentation factor $\alpha$ proposed by Blake (1972), accounts for a reduction in rock mass modulus, it can be computed through the equation (8):

$E_{\text {affer }}=E_{\text {before }} \times \alpha$ where $E_{\text {before }}$ and $E_{\text {after }}$ are the elastic modulus of rock before and after destress blasting, respectively; $\alpha$ ranges between 0 and 1 . When $\alpha$ is equal to one, the rock mass maintains nearly the same modulus of elasticity it had before destressing. When $\alpha$ is minimum (that is close to zero), it means that destress blasting has caused substantial softening of the rock mass. As the rock mass becomes softer after being destressed, it is plausible to suppose that the Poisson's ratio effect becomes greater. To this end, Tang and Mitri (2001) propose a simple expression to estimate the Poisson's ratio after destressing in terms of $\alpha$. This is given by equation (9).

$v_{\text {affer }}=v_{\text {before }} \times(2-\alpha)<0.5$

where $v_{\text {before }}$ and $v_{\text {after }}$ are Poisson's ratios before and after destress blasting. When $\alpha=1$, the Poisson's ratio after destressing remains the same. This is consistent with the equation (8). When $\alpha$ value is low the Poisson's ratio of the rock mass is almost doubled. In addition to equation 9, Tang and Mitri (2001) proposed a supplementary modelling parameter termed as the stress dissipation factor $\beta$, responsible for the instantaneous release of stresses from the rock immediately after the destress blast. This is represented by equation (10).

$\sigma_{\text {after }}=(1-\beta) \times \sigma_{\text {before }}$

where $\sigma_{\text {before }}$ and $\sigma_{\text {after }}$ are stresses within zones subjected to blast-induced damage before and after 
destress blasting. In the above equation, when $\beta=0$, it implies that the state of stress remains unchanged after destress blasting. In practice, this represents a situation where no stress or energy is dissipated from destressed zones. When $\beta=1$, it means that the energy and stress are dissipated considerably in the rock mass.

The present work carries out and compares three analyses. In the first analysis, the parameters $\alpha$ and $\beta$ are not applied, consequently simulating before destress blasting case. In the second analysis the $\alpha$ and $\beta$ are applied to the entire drift face volume affected by destress blasting, as shown in Fig. 7 (a) - thus simulating the traditional modelling approach of destress blasting suggested by Blake (1972) and Tang and Mitri (2001) with $\alpha$ value of 0.4 and $\beta$ value of 0.6 applied over almost the entire drift face, as shown in Fig. 7 (a). In the third analysis, the parameters $\alpha$ and $\beta$ are applied only to the individual damage zones as predicted by the 3D single-hole blast model, as shown in Fig. 7 (b). The values of $\alpha$ and $\beta$ are kept the same as in the second analysis. In the fourth analysis, destressing is modelled for the case of maximum damage achieved by destress blasting by assuming $\alpha=0.1$ and $\beta=0.9$ applied to the individual damage zones predicted by the single-hole blast model, as shown in Fig. 7 (b).

Figure 7. Estimated damaged zones for modelling destress blast damage: a) Traditional modelling approach; b) Individual blast damage zones.

\section{Drift destress blast simulation}

To simulate destress blasting practice at the case study mine, a finite difference code FLAC3D (Itasca 2009) is used. The 3D drift model and individual blast damage zones are constructed with the help of Kubrix (Itasca Consulting Group 2013). The drift dimensions are $4.5 \mathrm{~m} \times 4.5 \mathrm{~m}$. The individual blast damage zones are constructed for a charge length of 0.6 metre in the third analysis. The individual blast damage zones are ellipsoidally shaped with dimensions of $1.33 \mathrm{~m} \times 1.22 \mathrm{~m} \times$ $0.98 \mathrm{~m}$ for norite and $1.27 \mathrm{~m} \times 1.21 \mathrm{~m} \times 0.99 \mathrm{~m}$ for granite.

The models are solved with an isotropic linear elastic constitutive model in FLAC3D. As a first step, rock mass properties obtained from published literature (Malek et al. 2009) are applied in the models. The model boundaries are fixed in normal direction while the bottom of models is fixed in all directions. In-situ stress tensor values are computed at $2000 \mathrm{~m}$ depth and stresses are initialized in the model. Gravity is also enabled in the model. The model is solved for equilibrium condition, followed by extraction of a 20 -m-long drift and solving the model. This is followed by extracting one round of drift after destressing the designated zones by altering $\square$ and $\square$. The results are assessed after destressing two-rounds of drift development. 


\section{Results and discussion}

Numerical modelling of the drift at the case study mine shows that the drift face is under high stress, which may lead to strain burst. The results are shown in Fig. 8 in terms of major principal stress for the drift under consideration while simulating no destress blasting (first analysis). As can be seen, the stress value at the centre of the face is $93 \mathrm{MPa}$, and near the corners and sidewalls it is approaching $196 \mathrm{MPa}$ and $226 \mathrm{MPa}$, respectively. Destress blasting is then simulated with the traditional modelling approach employing $\alpha=0.4$ and $\beta=0.6$ (second analysis) and the results are shown in Fig. 9. It can be seen that the stress level is reduced significantly. The stress value at the centre of the drift face is around $74 \mathrm{MPa}$, while the stress near the corner and sidewall is $164 \mathrm{MPa}$ and $183 \mathrm{MPa}$ respectively. As anticipated, the results of the traditional modelling approach for destress blasting suggest lower stresses and fewer zones with high stress.

Figure 8. Major Principal Stress contours in the drift face before destressing.

Figure 9. Major Principal Stress contours in the drift face after destressing - traditional modelling approach.

In the third analysis, destress blasting is simulated by considering the individual blast damage zones as obtained from the single-hole model. The results of this analysis are shown in Fig. 10, in terms of major principal stress. It can be seen that the stress level is reduced after destress blasting, but only to $90 \mathrm{MPa}, 191 \mathrm{MPa}$ and 218 at the centre of drift face, corner and near the side walls respectively. Comparing these stress results with those of the second analysis, it can be established that the modelling approach considering blast damage zones leads to higher post-destress stresses than those obtained from the traditional modelling approach of uniform face damage.

Figure 10. Major Principal Stress contours in the drift face after simulating destress blasting modelling individual damage zones.

A numerical parametric study is performed to study the effect of rock type and destress blast efficiency. The mine development openings are hosted by norite and granite rock types. Both the rock types are studied in this work. As discussed earlier the average destress blasting simulation can be performed by considering $\alpha$ value of 0.4 and $\beta$ value of 0.6 . Efficient destress blasting 
456

457

458

459

460

461

462

463

464

465

466

467

468

469

470

471

472

473

474

475

476

477

478

479

480

481

482

483

484

485

486

487

488

489

490

simulation will translate in to $\alpha$ value of 0.1 and $\beta$ value of 0.9 .

This makes a total of three analyses for each rock type. Cases 1,2 and 3 are simulated for norite. The case 1 assumes that traditional modelling approach is performed. The case 2 assumes that average destress blasting is performed with modelling individual damage zones. The case 3 assumes that efficient destress blasting is performed with modelling individual damage zones. The cases 4, 5 and 6 are repetition of cases 1 to 3 with a change in rock type from norite to granite. The major principal stress values before and after destressing at the centre, near the side wall and corner of the drift face for norite and granite are shown in Table 4 and Table 5 respectively. A comparison of traditional modelling approach of destressing, average blast damage and maximum blast damage is also made in Table 4 and 5. Stress to strength ratio $\left(\sigma_{1} / \sigma_{c}\right)$ is also computed for all results after destress blasting. As can be seen, the maximum stress is accumulated for the case of average blast damage with modelling individual damage zones. Also, the ratio $\sigma_{1} / \sigma_{\mathrm{c}}$ is very high for drift side walls and corners. The value of $\sigma_{1} / \sigma_{\mathrm{c}}$ ratio at centre of the drift is lower for all the cases.

Table 4 and Table 5 show that both norite and granite acquire comparable stresses after simulating destress blasting. However the $\sigma_{l} / \sigma_{c}$ values are higher for norite than granite, because UCS of granite is much higher than norite. The stresses are higher near the sidewalls and corners even with simulating efficient destress blasting. The centre of the drift acquired relatively lower stress compared to drift sidewalls and corners for both the rocks.

Table 4. Maximum face stresses before and after simulating destress blasting for norite.

Table 5. Maximum face stresses before and after simulating destress blasting for granite.

The major stress in the walls, back and floor of the drift for simulating the drift before destress blasting, case 2 and case 3 are shown in Fig. 11. As can be seen in Fig. 11 a) the maximum stress in the drift wall is around $98 \mathrm{MPa}$ at a distance of $2 \mathrm{~m}$ in front of drift face. The stress in the centre of the back and floor is around $52 \mathrm{MPa}$ at a distance of $2 \mathrm{~m}$ in front of drift face. However the stress at the corners of back and floor are higher (around $240 \mathrm{MPa}$ ). Fig. $11 \mathrm{~b}$ ) and c) shows destress blasting simulation with modelling individual damage zones. As can be seen the wall stresses are reduced negligibly at respective locations due to smaller volume of destressed zones.

Figure 11. Major principal stress contours at the drift wall, floor and back for norite: a) No destressing; b) Case 2; c) Case 3.

The major principal stress values before and after destressing in the walls, floor and back of the drift for norite and granite are shown in Table 6 and 7, respectively. These values are recorded 2 
491 metres in front of the drift face, at the centre of the back, floor and walls. A comparison of average blast damage (case 2 and 5) and maximum damage ( 3 and 6 ) is also made in Table 6 and 7 for side walls, and roof and floor. Stress to strength ratio $\left(\sigma_{1} / \sigma_{c}\right)$ is also computed for all results after destress blasting. $\sigma_{1} / \sigma_{\mathrm{c}}$ values are very low for side walls, floor and back. As can be seen from Tables 6 and 7, the traditional modelling approach reduces the walls stresses and roof/floor stresses. Noticeably, the destress blasting simulation method with individual damage zones reduced stresses insignificantly.

498

Table 6. Maximum wall, floor and roof stresses before and after destressing for norite.

Table 7. Maximum wall, floor and roof stresses before and after destressing for granite.

These results show that the traditional modelling approach of destress blasting inherently over-estimates the volume of blast zones produced as a result of destress blasting. The over-estimation is sometimes extended to include the entire drift face. The new methodology of simulating destress blasting should include estimation of fragmented zones using the fully dynamic analysis under in-situ confined conditions with infinite burden for destress blasting holes. Then blast damage zones should be imported in the drift model and destress blasting should be simulated using $\alpha$ and $\beta$ parameters in accordance with equations (8), (9) and (10).

510 This research indicates that the current destress blasting practice may not lead to full-face stress

511 relief as originally intended. It is therefore recommended that the current practice be revisited, 512 with consideration to creating uniform blast energy distribution ahead of the face, e.g. by 513 increasing the number of destress holes. Consideration of adding notched drill holes without 514 explosives may also help in accelerating the initiation and development relaxation zones as the 515 notched holes are more likely to collapse faster than holes without notches under high stress 516 conditions, and fractures can more easily extend.

517 The efficiency of destress blasting can be examined through on-site stress measurements and 518 microseismic monitoring. This will help calibrate and validate the numerical model and can also 519 help optimize the destress blast design for maximum stress relief. This would be the next step in 520 this research.

\section{Conclusions}

523 The traditional modelling approach for destress blasting proposed by Blake (1972) and Tang and 524 Mitri (2001) is based on a holistic approach that considers that the area affected by destress 525 blasting is uniformly distributed ahead of the face with uniform reduced stiffness and reduced 526 stress factor. In this paper, an alternative approach for simulating destress blasting is examined. It 
527 considers only the damage zone caused by individual blastholes.

528 To accomplish that, a numerical model with a single blast hole is constructed and analyzed in 529 dynamic conditions whilst simulating destress blasting in order to investigate the extent of 530 blast-induced damage zone. The results obviously show that in-situ stress state exerts a large 531 influence on the extent of damage zones. In particular, damage zones extend deeper to the 532 surrounding rock mass in the direction of the maximum principal stress due to the lower confining 533 stress in the direction. More importantly, it is further shown that the damage zones mainly take 534 place within the blasted area and are proportional to a charge length at a rough estimate, 535 suggesting that the extent of damage zones for different charge lengths can be roughly estimated.

536 Based on the results, the efficiency of destress blasting is examined with a numerical model 537 encompassing a drift development. The rock fragmentation and stress dissipation factors are 538 adopted to simulate destress blasting for both the traditional and alternative modelling approaches. 539 It is shown that the traditional modelling approach may give an overly optimistic indication of 540 good destress blasting practice when compared with the alternative approach, in which a more 541 precise simulation of the damage zones is applied. Using the alternative modelling approach, it is 542 further found that even the maximum possible damage does not achieve a completely destressed 543 drift face.

544

\section{Acknowledgment}

546 This work is financially supported by NSERC Discovery Grants program. The authors are 547 grateful for their support. 


\section{References}

Abdellah, W., Mitri, H.S., Thibodeau, D., and Moreau-Verlaan, L. 2013. Stability of mine development intersections - a probabilistic analysis approach. Canadian Geotechnical Journal 51(2): 184-195. doi: 10.1139/cgj-2013-0123.

Adams, D.J., Gay, N.C., and Cross, M. 1993. Preconditioning: A technique for controlling rockbursts. In Rockbursts and Seismicity in Mines. Edited by R.P. Young. Balkema, Rotterdam. pp. 29-33.

Altindag, R., and Guney, A. 2010. Predicting the relatinsips between brittleness and mechanical properties (UCS, TS and SH) of rocks. Scientific Research and Essay 5(16): 2107-2118.

Andrieux, P.P., Brummer, R.K., Liu, Q., Simser, B.P., and Mortazavi, A. 2003. Large-scale panel blast at Brunswick mine. CIM Bull 96(1075): 78-87.

Banadaki, M.M.D., and Mohanty, B. 2012. Numerical simulation of stress wave induced fractures in rock. International Journal of Impact Engineering 40-41: 16-25.

Blake, W. 1972. Destressing test at the Galena Mine. In Transaction of SME-AIME. pp. 294-299.

Bolstad, D.D. 1990. Rockburst control research by the US Bureau of Mines. In Rockbursts and Seismicity in Mines. Edited by Fairhurst. Balkema, Rotterdam.

Brinkmann, J.R. 1987. Separating shock wave and gas expansion breakage mechanism. In 2nd International Symposium on Rock Fragmentation by Blasting. pp. 6-15.

Cho, S.H., Miyake, H., Kimura, T., and Kaneko, K. 2003a. Effect of the waveform of applied pressure on rock fracture process in one free-face. J. Sc. Tech. Energetic Mat. 64(3): 116-125.

Cho, S.H., Nishi, M., Yamamoto, M., and Kaneko, K. 2003b. Fragment size distribution in blasting. Materials Transactions 44(5): 951-956.

Cho, S.H., Ogata, Y., and Kaneko, K. 2003c. Strain-rate dependency of the dynamic tensile strength of rock. International Journal of Rock Mechanics and Mining Science 40: 763-777.

Emad, M.Z., Mitri, H., and Kelly, C. 2014. Effect of blast-induced vibrations on fill failure in vertical block mining with delayed backfill. Canadian Geotechnial Journal 51: 1-9.

Gool, B.v. 2007. Effects of blasting on the stability of paste fill stopes at Cannington Mine. James Cook University.

Hao, Y., and Hao, H. 2013. Numerical Investigation of the dynamic compressive behaviour of rock materials at high strain rate. Rock Mech. Rock Eng. 46: 373-388. 
Hongjian, W., Da'an, L., Weili, G., and Liyun, L. 2015. Dynamic analysis of granite rockburst based on the PIV technique. International Journal of Mining Science and Technology 25: 275-283.

Itasca. 2009. FLAC3D - fast Lagrangian analysis of continua. Itasca Consulting Group Inc. , U.S.A.

Itasca Consulting Group, I. 2013. Kubrix Ver. 12. Itasca, Minneapolis.

Itoh, S., Hamashima, H., Murata, K., and Kato, Y. 2002. Determination of JWL parameters from underwater explosion test. In 12th International Detonation Symposium.

Jaeger, J.C., Cook, N.G.W., and Zimmerman, R. 2007. Fundamentals of Rock Mechanics 4th edition. Wiley-Blackwell.

Jiang, J.J., Blair, D.P., and Baird, G.R. 1995. Dynamic respoinse of an elastic and viscoelastic full-space to a spherical source. International Journal for Numerical and Analytical Method in Geomechanics 19: 181-193.

Konicek, P., Soucek, K., Stas, L., and Singh, R. 2013. Long-hole destress blasting for rockburst control during deep underground coal mining. International Journal of Rock Mechanics and Mining Science 61: 141-153.

Kubota, S., Ogata, Y., Wada, Y., Simangunsong, G., Shimada, H., and Matsui, K. 2008. Estimation of dynamic tensile strength of sandstone. International Journal of Rock Mechanics and Mining Science 45: 397-406.

Lajtai, E.Z., Scott Duncan, E.J., and Carter, B.J. 1991. The effect of strain rate on rock strength. Rock Mech. Rock Eng. 24: 99-109.

Li, H., Li, J., B., L., Li, J., Li, S., and Xia, X. 2013. Direct tension test for rock material under different strain rates at quasi-static loads. Rock Mech. Rock Eng. 46: 1247-1254.

Lima, A.D.R., Romanel, C., Roehl, D.M., and Araujo, T.D. 2002. An adaptive strategy for the dynamic analysis of rock fracturing by blasting. In Computational Eng. \& Sci, Reno, Nevada.

Liu, L., and Katsabanis, P.D. 1997. Development of a continuum damage model for blasting analysis. International Journal of Rock Mechanics and Mining Science 34(2): 217-231.

Malek, F., Suorineni, F.T., and Vasak, P. 2009. Geomechanics Strategies for Rockburst Management at Vale Inco Creighton Mine. In ROCKENG09. Edited by M. Diederichs and G. Grasselli, Toronto.

Mazaira, A., and Konicek, P. 2015. Intense rockburst impacts in deep underground constructions and their prevention. Canadian Geotechnical Journal. doi: 10.1139/cgj-2014-0359. 
Mitri, H., and Saharan, M.R. 2005. Destress blasting in hard rock mines a state-of-the-art review. CIM Bull(1091): 85.

Mitri, H.S. 2001. Practitioner's Guide to Destress Blasting in Hard Rock Mines. McGill University.

O'Donnell, J.D.P. 1992. The use of destress blasting at Inco's Creighton Mine In MASSMIN 92. SAIMM, Johannesburg. pp. 71-74.

Qiu, S., Feng, X., Zhang, C., and Xiang, T. 2014. Estimation of rockburst wall-rock velocity invoked by slab flexure sources in deep tunnels. Canadian Geotechnial Journal 51: 520-539.

Roux, A.J., Leeman, E.R., and Denkhaus, H.G. 1957. Destressing: a means of ameliorating rock-burst conditions. Journal of South African Institute of Mining and Metallurgy 58: 104-146.

Saharan, M.R., and Mitri, H. 2011. Destress blasting as a mine safety tool: some fundamental challenges for successful applications. Procedia Engineering 26: $37-47$.

Saharan, M.R., and Mitri, H.S. 2009. Numerical Simulations for Rock Fracturing by Destress Blasting. VDM Verlag Dr. Muller Aktiengesellschaft \& Co. KG, Germany.

Sainoki, A., and Mitri, H.S. 2014. Numerical simulation of rock mass vibrations induced by nearby production blast. Canadian Geotechnial Journal. doi: 10.1139/cgj-2013-0480.

Sharafisafa, M., and Mortazavi, A. 2011. Numerical analysis of the effect of a fault on blast-induced wave propagation. In 45th U.S. Rock Mechanics / Geomechanics Symposium, San Francisco, California.

Snelling, P.E., Godin, L., and McKinnon, S.D. 2013. The role of geologic structure and stress in triggering remote seismicity in Creighton Mine, Sudbury, Canada. International Journal of Rock Mechanics and Mining Science 58: 166-179.

Tang, B. 2000. Rockburst control using destress blasting. Ph.D thesis, Department of Mining and Metallurgical Engineering, McGill University, Montreal, QC. .

Tang, B., and Mitri, H. 2001. Numerical modelling of rock preconditioning by destress blasting. Ground improvement 5: 1-11.

Vanichkobchinda, P., Reddish, D.J., Stace, L.R., and Whittles, D.N. 2007. Numerical simulation of the dynamic breakage characteristic of African norite. International JOurnal of Material \& Structural Reliability 5(2): 99-112.

Wang, J.-A., and Park, H.D. 2001. Comprehensive prediction of rockburst based on analysis of strian energy in rocks. Tunnelling and Underground Space Technology 16: 49-57. 
Wang, Z.L., Li, Y.C., and Shen, R.F. 2007. Numerical simulation of tensile damage and blast crater in brittle rock due to underground explosion. International Journal of Rock Mechanics and Mining Science 44: 730-738.

Wei, X.-y., and Zhao, Z. 2008. Response characteristics of underground rock cavern subjected to blast load. In World Tunnel Congress, India. pp. 665-673.

Wu, S., Wang, Y., Shen, D., and Zhou, J. 2012. Experimental study on dynamic axial tensile mechanical properties of concrete and its components. ACI Material Journal 109(5): 517-527.

Xia, K. 2013. A Mohr-Coulomb failure criterion for rocks subjected to dynamic loading. In Constitutive Modeling of Geomaterials, SSGG. Edited by Q. Yang. pp. 367-370.

Yun, X. 2008. Geomechanical behaviour of biaxially loaded rock. McGill University, Montreal, Canada.

Zhang, G., Jiao, Y., and Wang, H. 2014. Outstanding issues in excavation of deep and long rock tunnel: a case study. Canadian Geotechnial Journal. doi: 10.1139/cgj-2013-0087.

Zhao, G.-F., Russell, A.R., Zhao, X., and Khalili, N. 2014. Strain rate dependency of uniaxial tensile strength in Gosford sandstone by the distinct lattice spring model with X-ray micro CT. International Journal of Solids and Structures 51: 1587-1600.

Zhao, X.G., and Cai, M. 2014. Influence of specimen height-to-width ratio on the strianburst characteristics of Tianhu granite under tru-triaxial unloading conditions. Canadian Geotechnial Journal 52: 890-902.

Zhu, W.C., Wei, C.H., Li, S., Wei, J., and Zhang, M.S. 2013. Numerical modeling on destress blasting in coal seam for enahncing gas drainage. international Journal of Rock Mechanics and Mining Science 59: 179-190.

Zhu, Z., Mohanty, B., and Xie, H. 2007. Numerical investigation of blasting-induced crack initiation and propagation in rocks. International Journal of Rock Mechanics and Mining Science 44: 412-424. 
Figure captions

Figure 1. Stress profile ahead of a destressed drift face, modified after Tang (2000).

Figure 2. Schematic diagram showing damage zones induced by destress blasting.

Figure 3. Numerical model: (a) sectional view; (b) longitudinal sectional view.

Figure 4. Optimized pressure profile for ANFO type explosive for a $38 \mathrm{~mm}$ diameter borehole and schematic diagram showing propagation of detonation.

Figure 5. Extent of damage zones on cross sections, simulated with the model with 0.9 m charge length and the mechanical properties of granite: (a) damage zone on cross-section A shown in Fig. 3; (b) damage zone on cross-section B; (c) damage zone on cross-section B.

Figure 6. Destress blast pattern adopted by the case study mine: a) Longitudinal view; b) Side view; c) Plan view.

Figure 7. Estimated damaged zones for modelling destress blast damage: (a) Traditional modelling approach; (b) Individual blast damage zones.

Figure 8. Major principal stress contours in the drift face before destressing.

Figure 9. Major principal stress contours in the drift face after destressing - traditional modelling approach.

Figure 10. Major principal stress contours in the drift face after simulating destress blasting modelling individual damage zones.

Figure 11. Major principal stress contours at the drift wall, floor and back for norite: a) No destressing; b) Case 2; c) Case 3. 


\section{List of Tables}

Table 1. Rock mass mechanical properties.

Table 2. Destress blast hole specification chart.

Table 3. Input parameters for numerical model.

Table 4.Maximum face stresses before and after simulating destress blasting for norite.

Table 5. Maximum face stresses before and after simulating destress blasting for granite.

Table 6. Maximum wall, floor and roof stresses before and after destressing for norite.

Table 7. Maximum wall, floor and roof stresses before and after destressing for granite. 
Table 1. Rock mass mechanical properties.

\begin{tabular}{cccccccc}
\hline & $\begin{array}{c}\mathrm{E} \\
(\mathrm{GPa})\end{array}$ & $\begin{array}{c}\sigma_{\mathrm{c}} \\
(\mathrm{MPa})\end{array}$ & $\begin{array}{c}\phi \\
\left({ }^{\circ}\right)\end{array}$ & $v$ & $\begin{array}{c}\gamma \\
\left(\mathrm{kN} / \mathrm{m}^{3}\right)\end{array}$ & $\begin{array}{c}\sigma_{\mathrm{T}} \\
(\mathrm{MPa})\end{array}$ & $\begin{array}{c}\psi \\
\left({ }^{\circ}\right)\end{array}$ \\
\hline Granite & 60 & 240 & 63 & 0.26 & 25.5 & 16 & 8.75 \\
Norite & 78 & 190 & 59.1 & 0.28 & 28.0 & 12.6 & 8.75 \\
\hline
\end{tabular}

Table 2. Destress blast hole specification chart.

\begin{tabular}{ll}
\hline Drift advance & $1.83 \mathrm{~m}(6 \mathrm{ft})$ \\
Number of destress blast holes & 6 \\
Blast hole diameter & $0.1 \mathrm{~m}(0.33 \mathrm{ft})$ \\
Face hole length & $2.44 \mathrm{~m}(8 \mathrm{ft})$ \\
Corner hole length & $3.66 \mathrm{~m}(12 \mathrm{ft})$ \\
Charge length & $0.6 \mathrm{~m}(2 \mathrm{ft})$ \\
Charge diameter & $0.1 \mathrm{~m}(0.33 \mathrm{ft})$ \\
Explosive type & ANFO \\
Charge density & $0.9 \mathrm{~g} / \mathrm{cc}$ \\
VOD & $4700 \mathrm{~m} / \mathrm{s}$ \\
Priming method & Emulsion with bottom priming \\
Stemming & Drill cuttings throughout the length of hole \\
\hline
\end{tabular}


Table 3. Input parameters for numerical model.

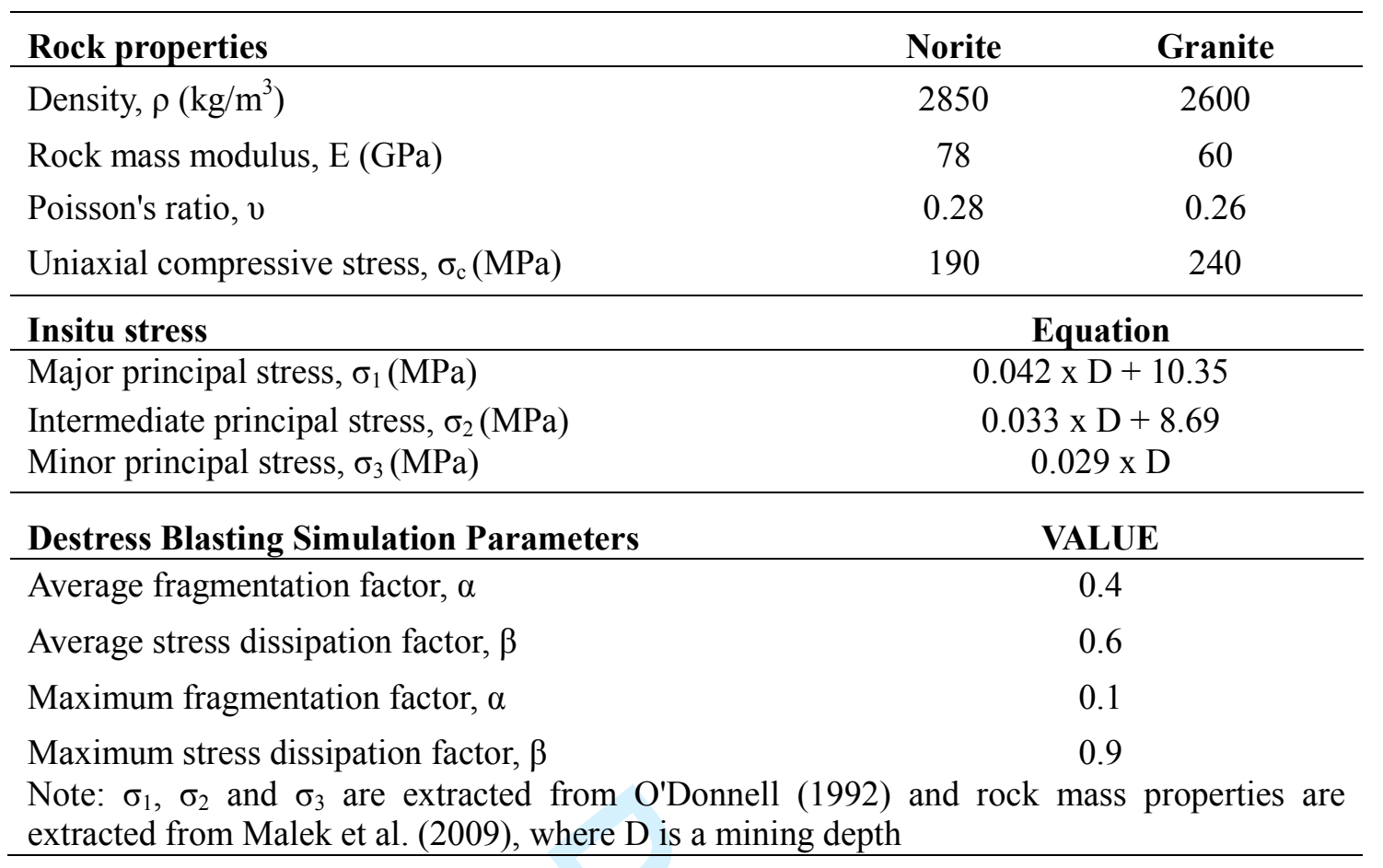

Table 4.Maximum face stresses before and after simulating destress blasting for norite.

\begin{tabular}{cccccccccc}
\hline & \multicolumn{3}{c}{ Near Sidewall (MPa) } & \multicolumn{3}{c}{ Near Corner (MPa) } & \multicolumn{3}{c}{ Centre (MPa) } \\
\cline { 2 - 10 } Case & Before & After & $\sigma_{1} / \sigma_{c}$ & Before & After & $\sigma_{l} / \sigma_{c}$ & Before & After & $\sigma_{1} / \sigma_{c}$ \\
\hline 1 & 191.4 & 148.8 & 0.78 & 177.4 & 141.3 & 0.74 & 93.1 & 74.0 & 0.34 \\
2 & 191.4 & 188.2 & 0.99 & 177.4 & 173.9 & 0.92 & 93.1 & 90.1 & 0.47 \\
3 & 191.4 & 182.5 & 0.96 & 177.4 & 170.3 & 0.90 & 93.1 & 88.5 & 0.47 \\
\hline
\end{tabular}

Table 5. Maximum face stresses before and after simulating destress blasting for granite.

\begin{tabular}{cccccccccc}
\hline & \multicolumn{3}{c}{ Near Sidewall $(\mathrm{MPa})$} & \multicolumn{3}{c}{ Near Corner $(\mathrm{MPa})$} & \multicolumn{3}{c}{ Centre $(\mathrm{MPa})$} \\
\cline { 2 - 10 } Case & Before & After & $\sigma_{l} / \sigma_{c}$ & Before & After & $\sigma_{l} / \sigma_{c}$ & Before & After & $\sigma_{l} / \sigma_{c}$ \\
\hline 4 & 189.8 & 144.3 & 0.60 & 173.7 & 137.3 & 0.57 & 92.2 & 60.2 & 0.25 \\
5 & 189.8 & 184.0 & 0.77 & 173.7 & 169.8 & 0.71 & 92.2 & 88.9 & 0.37 \\
6 & 189.8 & 181.1 & 0.75 & 173.7 & 163.1 & 0.68 & 92.2 & 86.1 & 0.36 \\
\hline
\end{tabular}


Table 6. Maximum wall, floor and roof stresses before and after destressing for norite.

\begin{tabular}{rrrrrrr}
\hline & \multicolumn{3}{c}{ Sidewall (MPa) } & \multicolumn{3}{c}{ Roof and Floor (MPa) } \\
\cline { 2 - 7 } Case & Before & After & $\sigma_{l} / \sigma_{c}$ & Before & After & $\sigma_{l} / \sigma_{c}$ \\
\hline 1 & 90.6 & 74.5 & 0.39 & 48.1 & 34.2 & 0.18 \\
2 & 90.6 & 84.2 & 0.44 & 48.1 & 46 & 0.24 \\
3 & 90.6 & 81.4 & 0.42 & 48.1 & 44.1 & 0.23 \\
\hline
\end{tabular}

Table 7. Maximum wall, floor and roof stresses before and after destressing for granite.

\begin{tabular}{rrrrrrr}
\hline & \multicolumn{3}{c}{ Sidewall (MPa) } & \multicolumn{3}{c}{ Roof and Floor $(\mathrm{MPa})$} \\
\cline { 2 - 7 } Case & Before & After & $\sigma_{1} / \sigma_{c}$ & Before & After & $\sigma_{1} / \sigma_{c}$ \\
\hline 4 & 84.3 & 73.3 & 0.31 & 46.2 & 32.7 & 0.14 \\
5 & 84.3 & 81.1 & 0.34 & 46.2 & 44.3 & 0.18 \\
6 & 84.3 & 79.9 & 0.33 & 46.2 & 42.8 & 0.18 \\
\hline
\end{tabular}




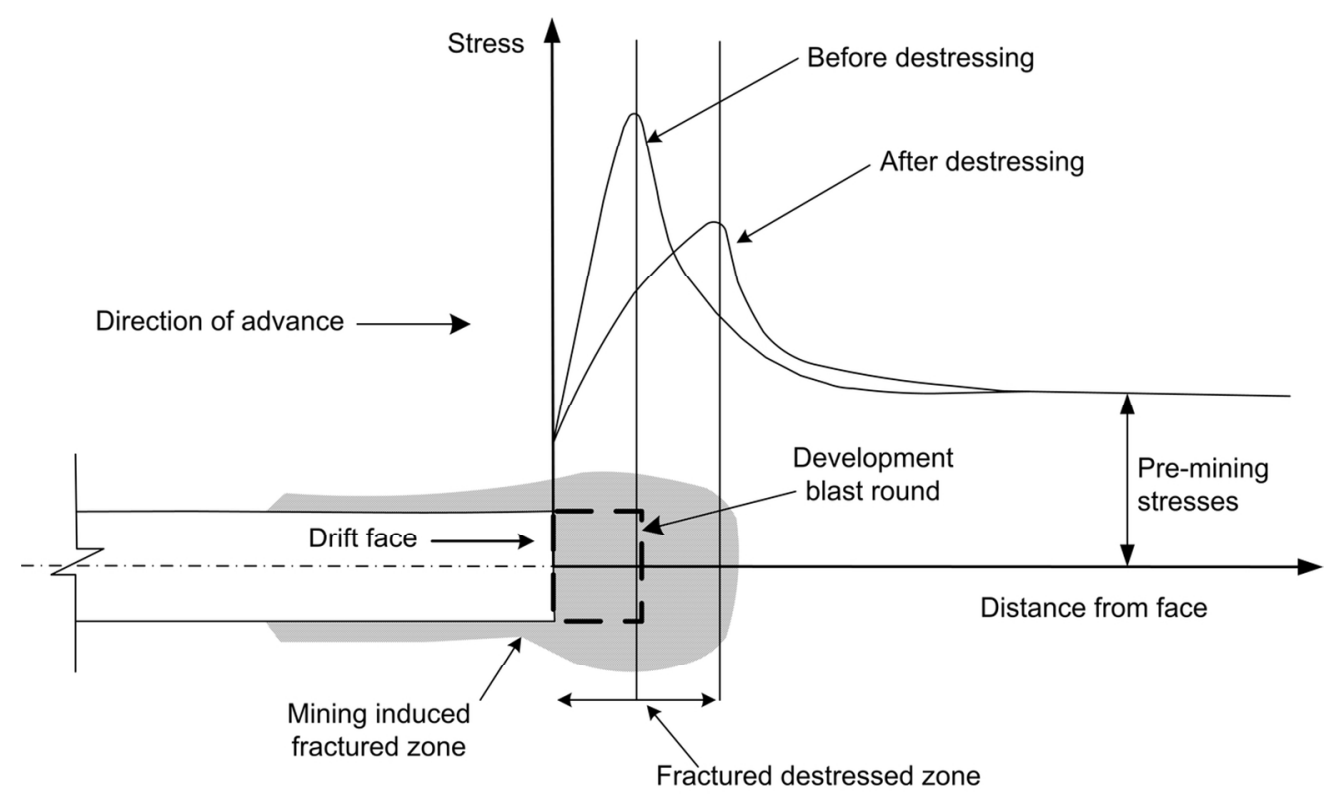

Figure 1. Stress profile ahead of a destressed drift face, modified after Tang (2000).

$120 \times 71 \mathrm{~mm}(300 \times 300 \mathrm{DPI})$ 


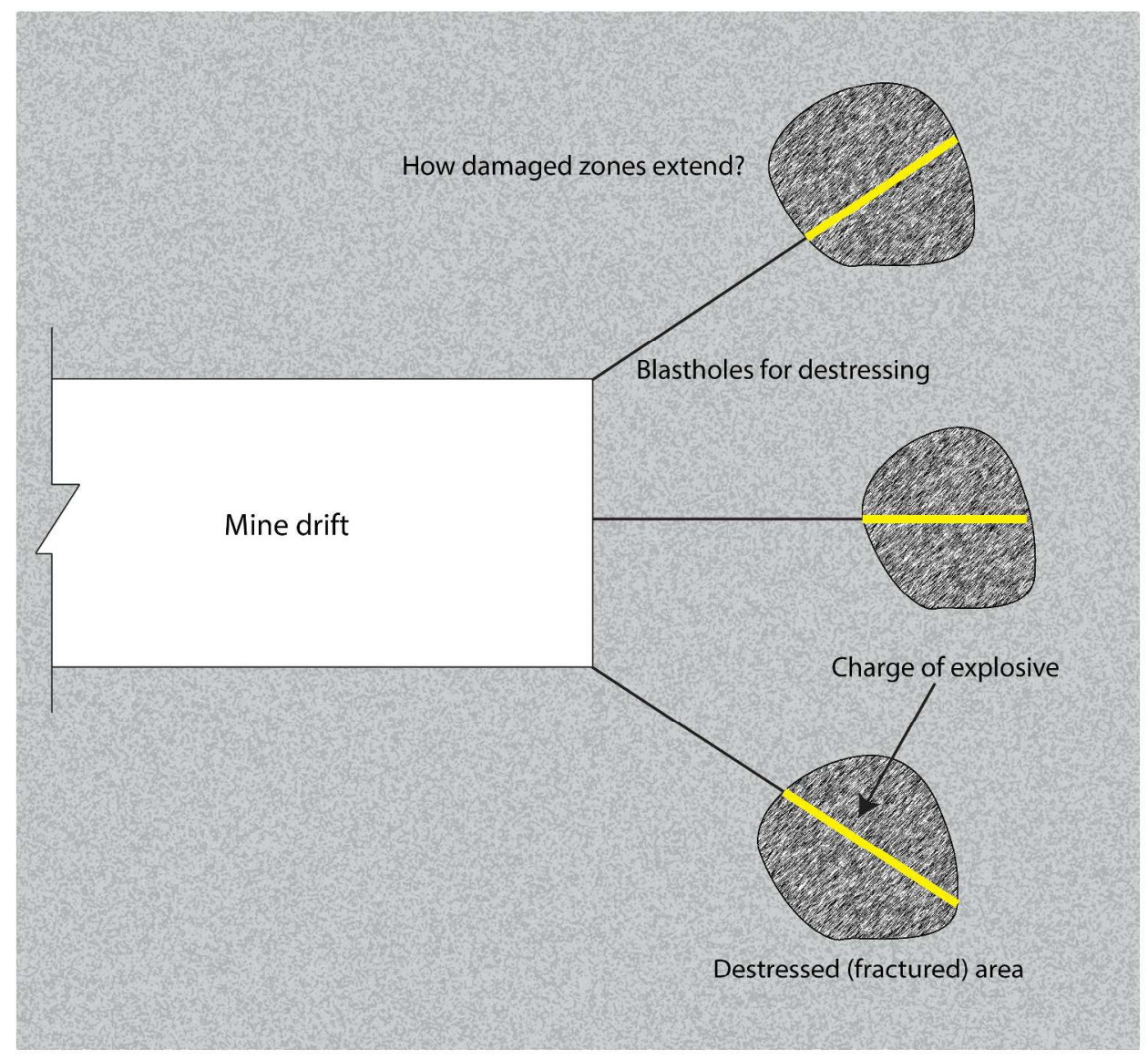

Figure 2. Schematic diagram showing damage zones induced by destress blasting. $299 \times 287 \mathrm{~mm}(300 \times 300$ DPI $)$ 


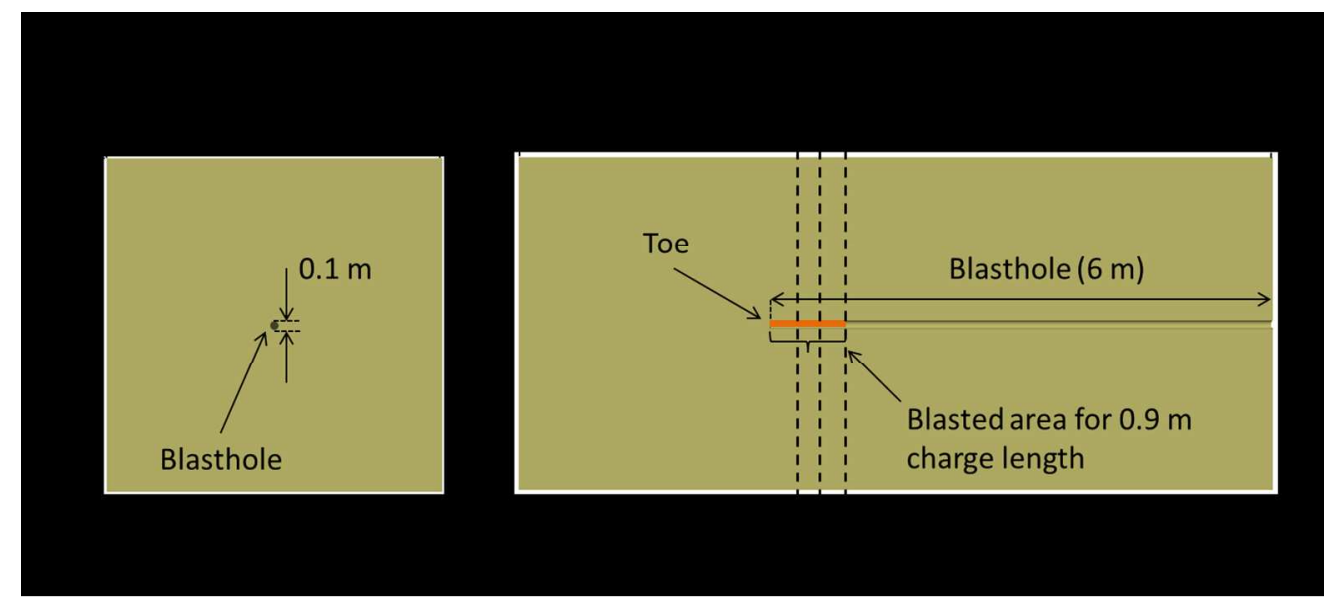

Figure 3. Numerical model: (a) sectional view; (b) longitudinal sectional view. $257 \times 115 \mathrm{~mm}(150 \times 150 \mathrm{DPI})$ 


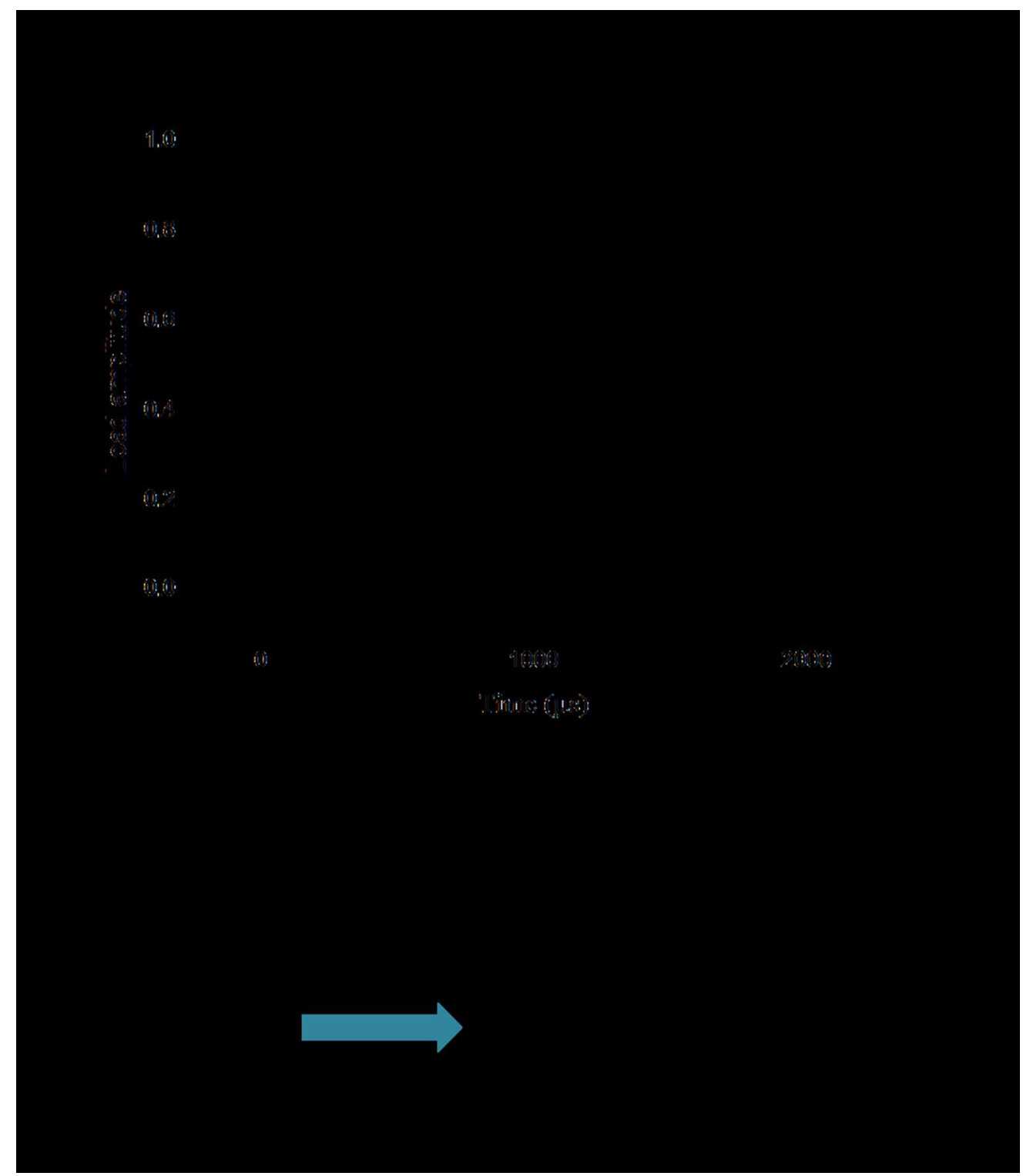

Figure 4. Optimized pressure profile for ANFO type explosive for a $38 \mathrm{~mm}$ diameter borehole and schematic diagram showing propagation of detonation.

$161 \times 187 \mathrm{~mm}(150 \times 150 \mathrm{DPI})$ 


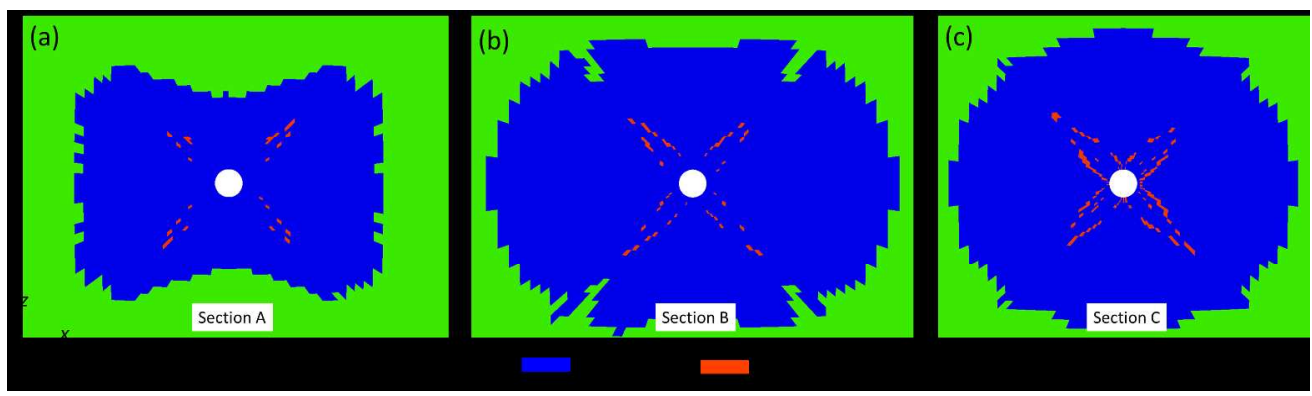

Figure 5. Extent of damage zones on cross sections, simulated with the model with 0.9 m charge length and the mechanical properties of granite: (a) damage zone on cross-section A shown in Fig. 3; (b) damage zone on cross-section $B$; $(c)$ damage zone on cross-section $B$.

$$
519 \times 151 \mathrm{~mm}(150 \times 150 \mathrm{DPI})
$$




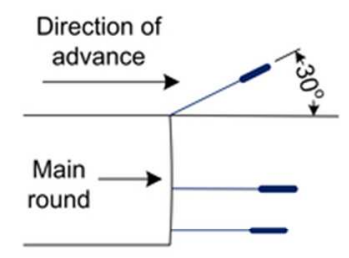

a)

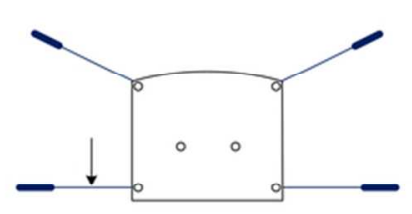

b)

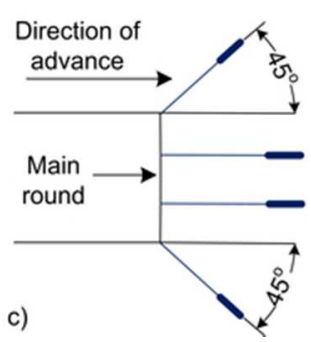

Figure 6. Destress blast pattern adopted by the case study mine: a) Longitudinal view; b) Side view; c) Plan view.

$65 \times 16 \mathrm{~mm}(300 \times 300$ DPI $)$ 


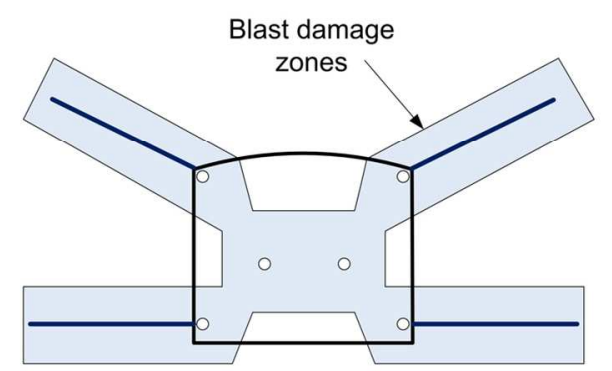

a)

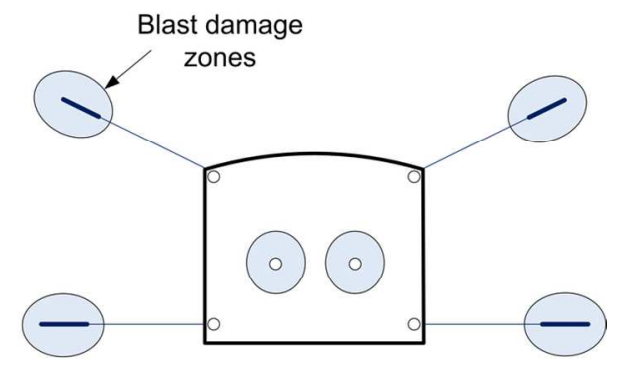

b)

Figure 7. Estimated damaged zones for modelling destress blast damage: (a) Traditional modelling approach; (b) Individual blast damage zones.

$127 \times 40 \mathrm{~mm}(300 \times 300 \mathrm{DPI})$ 


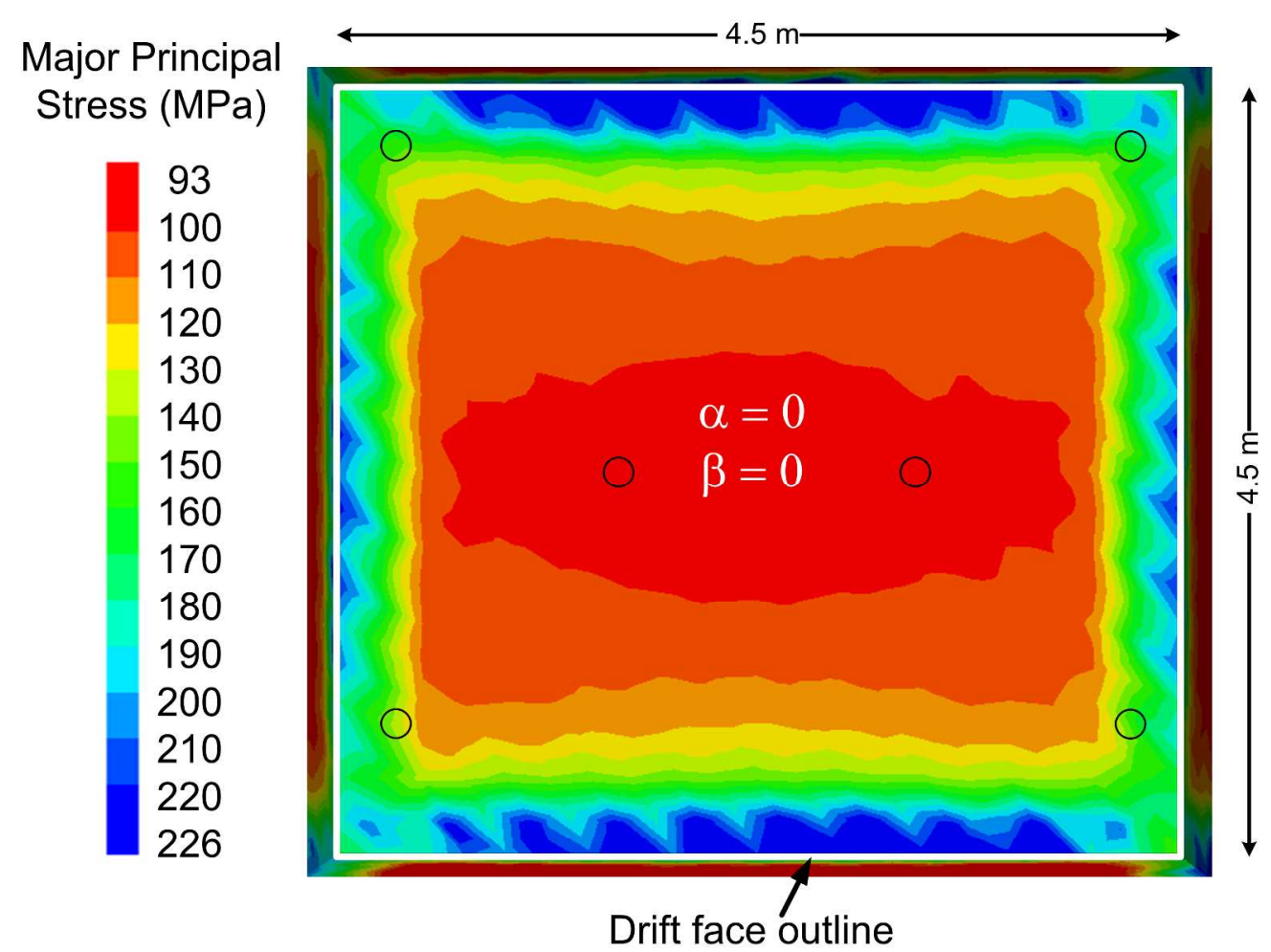

Figure 8. Major principal stress contours in the drift face before destressing. $266 \times 201 \mathrm{~mm}(300 \times 300$ DPI $)$ 


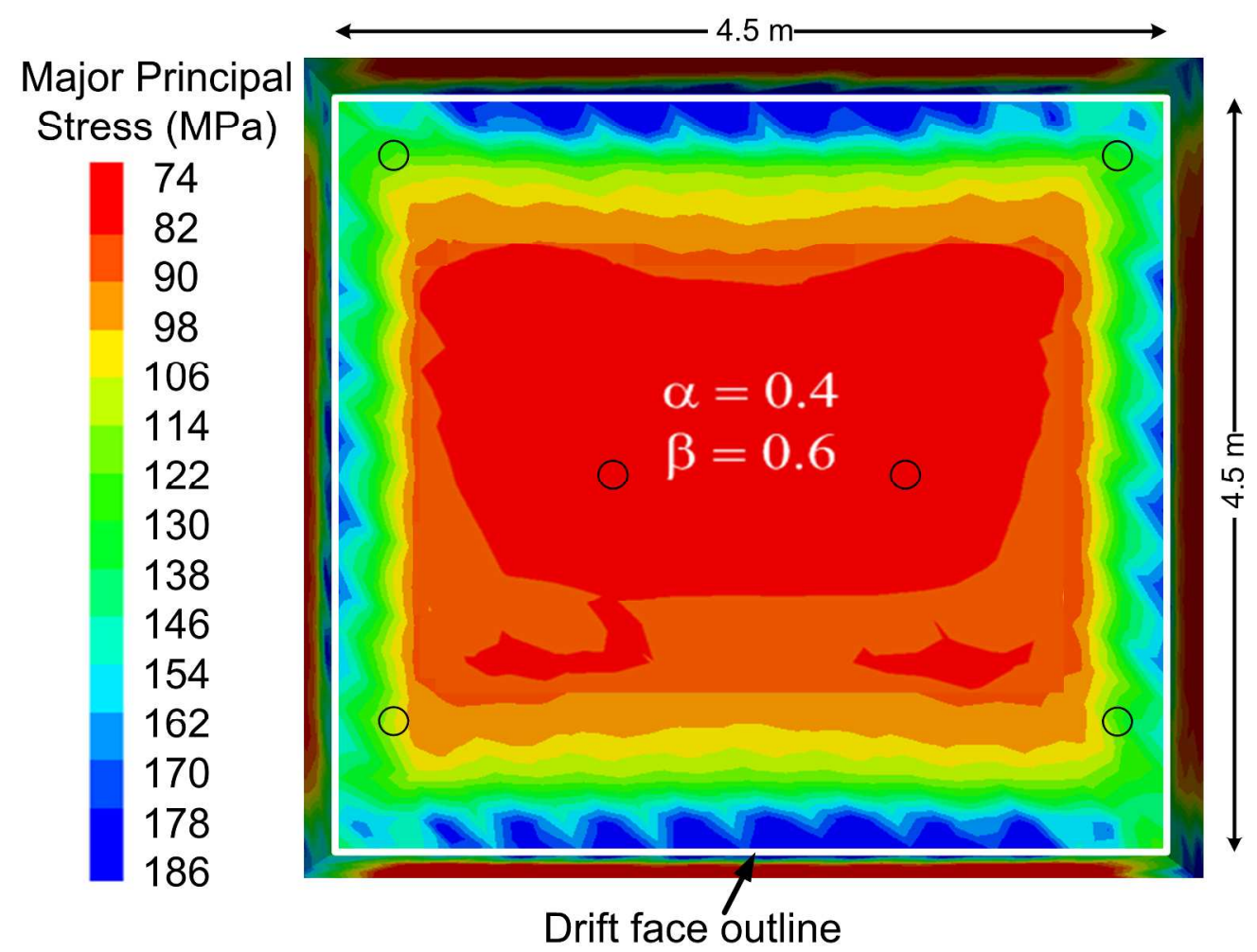

Figure 9. Major principal stress contours in the drift face after destressing - traditional modelling approach. $252 \times 193 \mathrm{~mm}(300 \times 300 \mathrm{DPI})$ 


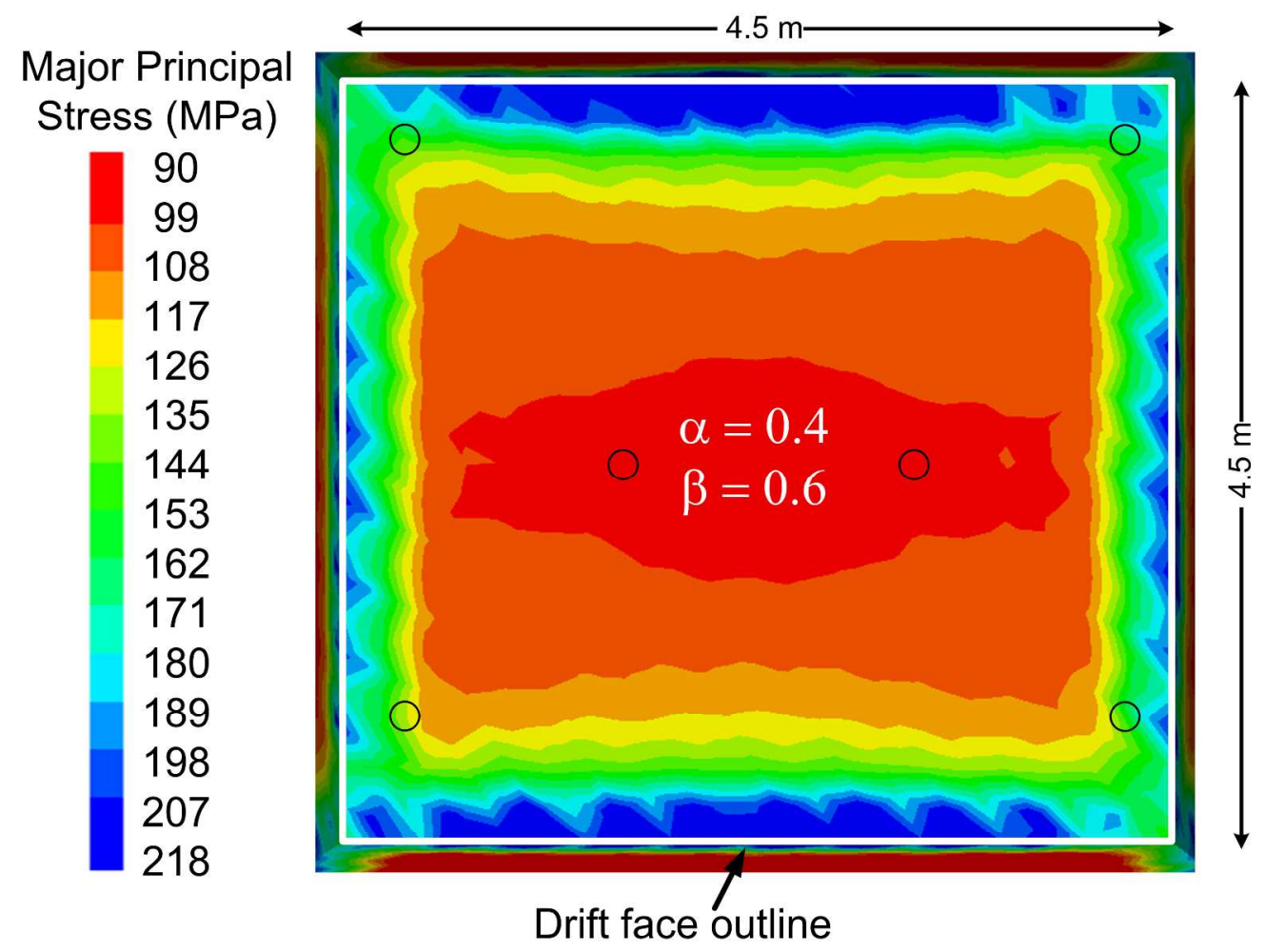

Figure 10. Major principal stress contours in the drift face after simulating destress blasting - modelling individual damage zones.

$254 \times 193 \mathrm{~mm}(300 \times 300 \mathrm{DPI})$ 


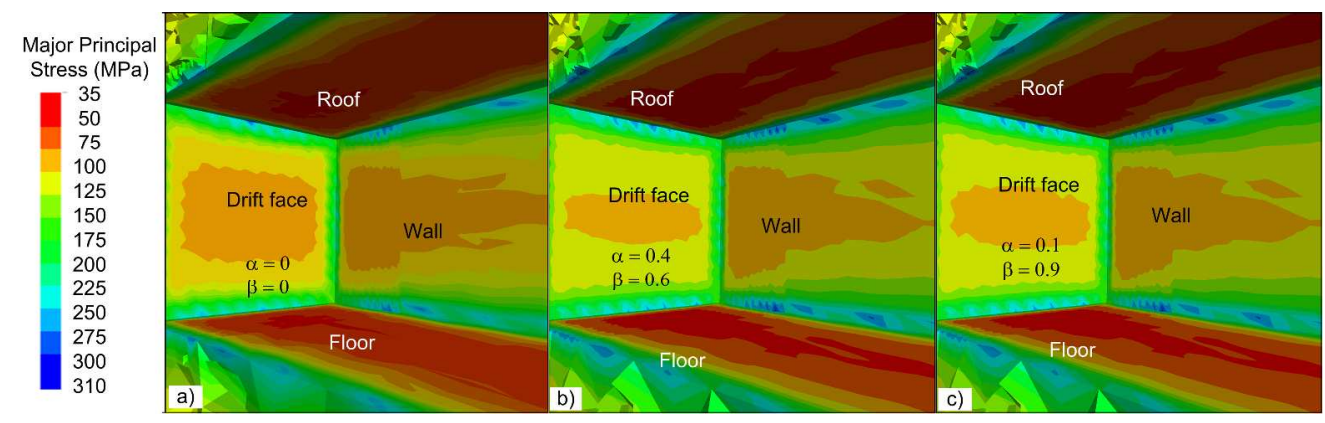

Figure 11. Major principal stress contours at the drift wall, floor and back for norite: a) No destressing; b) Case 2; c) Case 3.

$405 \times 125 \mathrm{~mm}(300 \times 300 \mathrm{DPI})$ 